\title{
PROBLEMATIZAC̣ÃO COMO ESTRATÉGIA PARA DISCUSSÃO SOBRE BIOÉTICA E BIOSSEGURANÇA NO ENSINO DE ZOOLOGIA: UMA EXPERIÊNCIA ENTRE LICENCIANDOS EM CIÊNCIAS BIOLÓGICAS
}

\author{
Kênio Erithon Cavalcante Lima*
}

RESUMO: A preocupação com o bem estar animal determina mudanças de atitude nas atividades de ensino e pesquisa envolvendo animais. Isto levou ao desenvolvimento de recursos didáticos alternativos para reduzir o sofrimento imposto a animais. Este trabalho investigou concepções de alunos de Ciências Biológicas sobre conceitos de Bioética e Biossegurança no manuseio de animais na UFPE. Observou-se que a maioria dos estudantes ignora aspectos da senciência e bem estar animal e também os riscos à saúde decorrentes da manipulação de animais. Faltam situações formais (disciplinas) e atividades extracurriculares que estimulem a percepção da Bioética e da Biossegurança no ensino de Biologia.

Palavras-chave: Bem-estar Animal; Ensino de Biologia; Recursos Didáticos Alternativos.

PROBLEMATIZATION AS STRATEGY FOR DISCUSSING BIOETHICS AND BIOSAFETY APPLIED TO ZOOLOGY TEACHING: AN EXPERIENCE AMONG BIOLOGICAL SCIENCE STUDENTS

ABSTRACT: Concern about animal welfare instigates attitude changes in teaching and research activities involving animals. This has led to the development of alternative didactic resources aimed to reduce animal suffering. This work investigated conceptions from Biological Sciences students related to Bioethics and Biosafety applied to animal manipulation at UFPE. We observed that most students ignore aspects of sentience and animal welfare and also risks to human health when dealing with animals. There is a shortage of formal situations (courses) and extracurricular activities that stimulate perceptions about Bioethics and Biosafety in Biology teaching.

Keywords: Animal Welfare; Biology Teaching, alternative didactic resources
${ }^{*}$ Mestre em Ensino das Ciências (Conceito CAPES 4) . Universidade Federal Rural de Pernambuco (UFRPE). Professor Assistente da Universidade Federal de Pernambuco (UFRPE). Email: keclima@ig.com.br 


\section{INTRODUĈ̣̃O}

Muitas das conquistas da biologia e da saúde foram, e ainda são, alcançadas pela manipulação de animais cobaias que, submetidos às mais diversas formas de experimentação, passam a ter direitos esquecidos (GARRAFA, 2001; PAIXÃO, 2001; SILVA, 2002) "em prol da ciência”, justificados pela melhoria da qualidade de vida que os resultados dessas experimentações proporcionam. Mas melhoria da qualidade de vida de quem? Em sua história, o homem vem realizando diversas experimentações com animais, que beneficiaram e beneficiam as mais diversas formas de vida existentes (GALLIAN, 2005; HOUGHTON et al., 2005; SILVA, 2002), contudo muitas dessas conquistas ocorreram e ocorrem à custa do sofrimento e/ ou da própria vida de animais que, expostos às mais diversas formas de crueldades, expressam reações de "dor" (LABARTHE et al., 2005; LUNA, 2008; PAIXÃO, 2001; RAYMUNDO; GOLDIM, 2002; SINGER, 2004; SOUTO, 2000).

$\mathrm{O}$ modo com que diversos animais são tratados em atividades de pesquisa e/ou criatórios fortalece discussões sobre os limites da experimentação e da manipulação de animais (BASTOS et al., 2002; GARRAFA, 2001; SILVA, 2002). Em muitas das atividades de ensino superior ou básico, os animais são utilizados para a formação ou comprovação de conceitos científicos e o aperfeiçoamento das habilidades práticas na zoologia e/ou biologia humana (BASTOS et al, 2002). Entretanto, as reações externadas por esses animais pouco despertam preocupações éticas nas pessoas que os manipulam (FEIJÓ et al., 2008).

$\mathrm{Na}$ licenciatura em Ciências Biológicas, a discussão ainda não assume a relevância necessária, pois muito do que é ensinado na formação dos graduandos é aplicado na docência no ensino básico das Ciências e da Biologia (MORAES, 2005). Isso ocorre porque, de acordo com Quadros et al. (2005), os docentes formadores representam referenciais didático-metodológicos e pedagógicos para os docentes em formação. Pelo uso constante de animais em atividades práticas na formação, os docentes formadores induzem ao desconhecimento de outros recursos possíveis de aplicação alternativa / substitutiva. Dessa forma, contradizem perspectivas mundiais que repensam atitudes de preservação e conservação dos ambientes e o que resta da fauna e da flora (BRASIL, 1988; BRASIL, 1998; CFBio, 2002; IBAMA, 2009; MACHADO, et al., 2004).

Para contornar diversas situações de exploração animal em ambientes de pesquisa e ensino, defensores dos direitos e do bem estar dos animais expõem e discutem a Bioética animal como tentativa de resguardar direitos esquecidos e/ou ignorados, quando pesquisadores e docentes perpetuam abusos e menosprezam orientações para o uso de procedimentos alternativos / substitutivos, o que amplia as atitudes de crueldade contra os animais (GARRAFA, 2001; LABARTHE et al., 2005; PAIXÃO, 2005; RIVERA, 2002; SINGER, 2004). Inicialmente, a Bioética surge para combater abusos em crimes de guerra e nas experimentações com humanos; mas recentemente, ela discute princípios e atitudes em prol do bem estar animal na pesquisa e no ensino (CFBio, 2002; DINIZ et al., 2006; FEIJÓ et 
al., 2008). O termo Bioética restringe ações dolosas determinadas pelo homem a outros animais pela primazia de não lhes impor dor e sofrimento (LUNA, 2008; PIMENTA; SILVA, 2001; RIVERA, 2002; SINGER, 2004; SOUTO, 2003).

Em Lima et al. (2008), consta que, na graduação de licenciandos das Ciências Biológicas, pouco se discute sobre o ensino da Bioética Animal, e os princípios que fundamentam as atitudes docentes dos licenciandos e as limitações necessárias do ser humano sobre outros animais não humanos. São procedimentos ignorados, ao mesmo tempo intensificados, quando os docentes das Ciências e da Biologia desconhecem ou desprezam a senciência de muitos animais, pois, segundo Singer (2004), muitas das expressões de dor e sofrimento dos animais não são externadas e nem observadas por serem expressões privadas. Como consequência do desconhecimento e do desprezo da senciência de muitos animais, predomina, nas atividades práticas de ensino, a utilização de animais como recurso didático-metodológico para discutir ou comprovar conceitos específicos e/ou treinamento técnico e de metodologia da pesquisa (DINIZ et al., 2006; PAIXÃO, 2001; RIVERA, 2002), em detrimento de outros procedimentos menos dolosos. Por essa carência de enfoque pertinente ainda na formação de licenciandos, despreza-se o paradigma da Bioética que "hoje, tem o dever de promover o debate sobre tais questões, rejeitando e criticando soluções simplistas para perguntas cada vez mais complexas" (TELLES, 2003, p.196).

Além da Bioética animal, outro conceito, a Biossegurança, fundamenta orientações para o manuseio correto de animais em atividades práticas. Inicialmente, o termo enfatizava os riscos e as ameaças de guerra com armas biológicas e as consequências da manipulação genética, avaliando os riscos da liberação dos OGMs no ambiente (ANVISA, 2008). Percebe-se nitidamente uma preocupação com as relações políticas e com as atividades restritas da pesquisa. Contudo, atualmente, já se questionam os riscos da manipulação de material biológico nos mais diversos ambientes de pesquisa e ensino, pela existência de animais e plantas potencialmente vetores de patógenos e de toxinas (CUPO et al., 1991; LIMA; VASCONCELOS, 2006; TEIXEIRA; VALLE, 2003). Reorientam-se procedimentos para atividades de ensino, tendo em vista a presença de alunos inexperientes e imaturos , alguns ainda crianças em processo de formação básica, que participam das atividades.

Ainda que se argumente sobre a necessidade de aplicação de poucas atividades de ensino com o uso de animais, a inserção de recursos didático-metodológicos alternativos / substitutivos no ensino de ciências e biologia na educação básica ainda é insignificante (LIMA et al., 2008). Por tais carências, amplia-se a responsabilidade das Instituições de Ensino Superior (IES) e de seus formadores em aplicar, ainda na formação dos licenciandos, os pressupostos de uma educação comprometida (GIOVANI, 1998), embasada nos princípios Bioéticos e de Biossegurança animal para ampliar ações consistentes no Ensino Superior e Básico.

\section{A legislação e o uso de animais em atividades de ensino}

No Brasil, em comparação a outros países, a legislação que regulamenta e 
limita o uso de animais em experimentação, pesquisa e ensino é ainda insuficiente para garantir aos animais respeito e ao homem punição por seus abusos. A mais recente publicação oficial, a Lei n. 11.794 de 08 de outubro de 2008 (BRASIL, 2008), orienta para o uso científico de animais e regulamenta o Artigo 225, $\int^{\circ}$, alínea VII da Constituição Brasileira de 1988 (BRASIL, 1988). O referido artigo responsabiliza o Poder Público por "proteger a fauna e a flora, vedadas, na forma da lei, as práticas que coloquem em risco sua função ecológica, provoquem a extinção de espécies ou submetam os animais a crueldade".

O Artigo 29 da Lei n. ${ }^{\circ} 9.605 / 1998$ (BRASIL, 1998), complementada no Decreto n. ${ }^{\circ} 3.179 / 1999$ (BRASIL, 1999a), define como crimes ambientais contra a fauna: "matar, perseguir, caçar, apanhar, utilizar espécimes da fauna silvestre, nativos ou em rota migratória, sem a devida permissão da autoridade competente, ou em desacordo com a obtida" (BRASIL, 1998). Tendo em vista o constante nos documentos anteriormente apresentados (BRASIL, 1988; 1998), percebe-se a existência de normativas que deveriam proteger a fauna, o que não exclui nenhum dos Filos do Reino Animal. Porém, a Lei n. 11.794 (BRASIL, 2008), explicitamente destina-se a orientar a manipulação de animais vertebrados, não restringindo e nem orientando o uso dos invertebrados que, conforme Singer (2004) e Souto (2003), possuem espécies com níveis de senciência variável e perceptível. Contudo, ainda que deixe brechas, permitindo assim a utilização de invertebrados como artrópodes e moluscos em atividades práticas de ensino de Ciências e Biologia na formação básica, a Lei n. 11.794 também determina que: "sempre que possível, as práticas de ensino deverão ser fotografadas, filmadas ou gravadas, de forma a permitir sua reprodução para ilustração de práticas futuras, evitando-se a repetição desnecessária de procedimentos didáticos com animais" (BRASIL, 2008, p.5).

$\mathrm{Na}$ ausência de documentos legais da Federação e dos Estados, ou pela inconsistência e/ou limitação na legislação existente, fica a cargo de entidades e instituições como o COBEA (2007) (Colégio Brasileiro de Experimentação Animal) e conselhos específicos, como o Conselho Federal de Biologia (CFBio), orientar a boa prática e referenciar a atuação do Biólogo pesquisador ou docente. Por sua especificidade, o Código de Ética do Biólogo (CFBio, 2002) determina em seu Artigo 13 que: "caberá ao Biólogo, principalmente docentes e orientadores, esclarecer, informar e orientar os estudantes de Biologia [...] sobre os princípios e normas deste Código de Ética". Assim, a legislação responsabiliza as IES formadoras dos Biólogos Bacharéis e Licenciados e seus professores pela apropriarção e pela aplicação dos princípios desse Código de Ética junto a seus graduandos. Em outras orientações, antes mesmo da Lei n. 11.794, o CFBio já recomendava o uso de recursos alternativos / substitutivos, sempre que possível, em atividades práticas de ensino e de pesquisa com manuseio de animais.

\section{Atividades práticas na construção da aprendizagem}

Acreditamos que as atividades práticas aplicadas no ensino das Ciências 
e da Biologia criam situações favoráveis ao ensino-aprendizagem dos conceitos (AUSUBEL et al., 1980; BRASIL, 2002; KRASILCHIK, 2004). Porém, se não são bem planejadas, sem objetivos definidos, servem apenas para comprovar teorias facilmente alcançadas por outros recursos, ou para exibições inconsistentes e desnecessárias, o que não contribui com a construção de diferentes saberes por parte dos alunos participantes da atividade pedagógica. Por uma atitude de mudança compatível com a Bioética e com a Biossegurança animal, as IES, os professores formadores e os professores de ciências e biologia obrigam-se a reavaliar hábitos e atitudes que transformem e inovem a própria prática docente. Para isso, acreditamos, deverão reavaliar também as atividades práticas com animais, evitando a repetição de erros que ignoram a senciência daqueles. Assim, os docentes que objetivam manipular animais no ensino das ciências necessitam aprofundar leituras em parâmetros como a LDB (BRASIL, 1996), dos PCN (BRASIL, 1999b), PCN+ / Biologia (BRASIL, 2002) e OCEM/Biologia (2006). Acreditamos que tais parâmetros orientarão os docentes das Ciências Naturais a desenvolver e aplicar mecanismos em prol de estratégias e uso de recursos alternativos, com consciência Bioética e com Biossegurança quanto à aprendizagem do conhecimento científico, dando aos educadores a possibilidade de se colocarem como profissionais críticos e reflexivos diante dos desafios de instruir, pela educação, a cidadania na sala de aula (DIAS-DA-SILVA, 1998).

O diferencial se dá quando as orientações pertinentes são discutidas ainda na formação dos licenciandos, disponibilizando-lhes condições como o ensino de estratégias para a elaboração e a aplicação de recursos/técnicas didático-metodológicos diferenciados que dispensem o uso constante e obrigatório de animais como objetos de estudo no ensino básico. Contudo, nesse campo conceitual, ainda existem lacunas, as quais nos propomos a investigar para compreender que concepções conceituais os licenciandos em Ciências Biológicas possuem e aplicam sobre Bioética e Biossegurança.

Como objetivos, buscou-se: a) analisar as orientações de Bioética e de Biossegurança que os licenciandos dariam a seus alunos do ensino básico em possíveis situações de captura, manuseio e conservação de animais em atividades práticas de ensino; b) identificar propostas de recursos alternativos / substitutivos sugeridas pelos licenciandos para o não uso de animais no ensino de Zoologia.

\section{METODOLOGIA}

\section{Amostragem}

A pesquisa teve como público alvo licenciandos em Ciências Biológicas do Centro de Ciências Biológicas da Universidade Federal de Pernambuco, Recife - PE. Como instrumento de pesquisa, usamos um questionário (apêndice 1). As coletas ocorreram nos anos de 2006 e 2008, com licenciandos que voluntariamente responderam às questões propostas, o que resultou em duas amostragens. 
A primeira amostragem é constituída de $\mathrm{N}=13$ licenciandos $(81,3 \%)$, de um quantitativo de $\mathrm{N}=16$, que cursavam a disciplina Prática de Ensino em Ciências Biológicas I (2006.2) e a segunda, constituída de $\mathrm{N}=21$ licenciandos (47,7\%), de um quantitativo de $\mathrm{N}=44$, matriculados na disciplina Prática de Ensino em Ciências Biológicas II (2008.2). A amostragem é, então, representada por um quantitativo de 34 licenciandos, diferenciados em função dos anos e períodos em que cursaram as disciplinas. As práticas de ensino (I e II) são ministradas para licenciandos que cursam os últimos períodos e que já cumpriram todas as disciplinas obrigatórias de Zoologia e Ecologia, assim como algumas das eletivas dessas duas áreas de conhecimento.

\section{Perfil do curso}

O curso de Licenciatura em Ciências Biológicas da Universidade Federal de Pernambuco (UFPE) é relativamente novo, pois foi criado em 1996 com o objetivo principal de atender egressos do Ensino Básico que trabalham no período diurno. A grade curricular do curso constitui-se de disciplinas obrigatórias e eletivas de caráter multidisciplinar.

As áreas de Zoologia e Ecologia apresentam disciplinas eletivas (optativas) como Impacto Ambiental, Biologia Marinha, Aracnologia, Controle Biológico de Insetos, Venenos Animais, Poluição e Meio Ambiente, Sistemática e Evolução, além das obrigatórias: Zoologia dos Invertebrados Inferiores (60 horas/aula, $3^{\circ}$ período), Zoologia dos Invertebrados Superiores (60 horas/aula, 4o período), Zoologia dos Vertebrados (75horas/aula, 5o período) e Ecologia Geral (60 horas/ aula, 4o período). Essas disciplinas comumente utilizam-se de coleções didáticas com animais (insetos, peixes, répteis, aves, mamíferos e preparações de elementos da microfauna marinha), além de realizar dissecações para a formação ou reforço de conceitos zoológicos dos licenciandos.

\section{Aplicação e análise}

Os licenciandos responderam a uma situação hipotética proposta (Apêndice 1), e foram identificados por códigos, a saber: L1.6 para o licenciando L1 do período 2006.1 e L5.8 para o licenciando L5 do período 2008.2, mantendo-se, assim, o anonimato dos voluntários da pesquisa, com o objetivo de aumentar a confiabilidade nas respostas. Suas respostas foram categorizadas a posteriori, analisadas e discutidas com base na compreensão de categorização defendida por Bardin, (2004), que a classifica como "elementos constitutivos de um conjunto, por diferenciação e, seguidamente, por reagrupamento segundo o gênero (analogia), com os critérios previamente definidos" (p.111). As respostas foram, então, agrupadas por possuírem significância, "tendo como primeiro objetivo (da mesma maneira que a análise documental) fornecer, por condensação, uma representação simplificada dos dados brutos" (IBID, p.112-113).

O quadro das categorias é constituído da coluna dos licenciandos favoráveis e a dos não favoráveis às coleções zoológicas para o ensino, classificados pelo teor de suas respostas, o que possibilita compreender as atitudes e percepções que 
são mais significativas em cada amostragem. A ordem das categorias se fez das que sugerem uso constante de animais para as que trazem propostas de recursos alternativos / substitutivos ao uso de animais nas atividades práticas de ensino. Ao longo do texto, são transcritos fragmentos das respostas dos licenciandos para maior veracidade das categorias.

\section{RESULTADOS E DISCUSSÃO}

Com a análise das respostas dos licenciandos, observa-se que 35,3\% $(\mathrm{N}=12)$ são favoráveis às coleções zoológicas para o ensino, distinguindo-se de uma maioria, 64,7\% (N=22), que não defende a necessidade do uso das coleções (Quadro 1). Contudo, mesmo os favoráveis às coleções biológicas sugerem mecanismos e procedimentos diversos condizentes com os princípios da Bioética e de Biossegurança. Revelaram consciência e preocupação com o bem estar animal nas diversas atividades práticas de ensino, semelhantes às dos licenciandos não favoráveis às coleções biológicas. Por tais resultados parciais, defendemos como pertinente a ampliação da discussão desta pesquisa com o estudo das categorias (Quadro 1), tendo em vista que o uso e manipulação de animais em atividades práticas em diversas modalidades de ensino é uma metodologia ainda comum (BASTOS et al., 2002; VENTURA; PANIZZI, 1997), conforme constatado nas respostas dos licenciandos ao problema proposto.

Com o estudo mais detalhado das categorias construídas a posteriori pela interpretação e aglutinação das respostas dos licenciandos, percebe-se que as concepções predominantes entre eles são condizentes com a prática adequada da Bioética, ou seja, que defende o uso limitado de animais, a preocupação com o ambiente e a possibilidade de uso constante de recursos alternativos / substitutivos para o ensino-aprendizagem dos conceitos zoológicos (Categorias III, VIII e X Quadro 1). Porém, poucos licenciandos esboçam preocupações com o sofrimento dos animais e com os riscos de acidentes quando da manipulação destes, com a importância ecológica e com os efeitos que a coleta dos animais para as coleções zoológicas determina ao meio ambiente. Desprezam ou desconhecem que as coleções zoológicas (entomológicas ou de outros animais conservados em soluções líquidas ou empalhados) são comumente constituídas por animais de espécies coloridas e de belezas intensas, muitos destes ameaçados de extinção (IBAMA, 2009), o que agrava as relações ecológicas já prejudicadas por outras ações humanas.

O descaso é constatado pela concepção de um dos adeptos às coleções (L8.8 -Categoria I), que compreende o uso de animais em atividades práticas como "uma forma de fixar e aprender na prática as definições e conceitos, pois a aula prática interliga o ensino ao cotidiano e a outros aspectos, de forma que desperta o interesse do aluno". É uma indagação que tem no contexto da resposta fortes traços de uma formação superior com práticas reprodutivas, com procedimentos que negam outras estratégias, não percebendo que a aprendizagem também se faz 
por recursos e metodologias diversificadas. E mesmo que sejam feitas, os responsáveis devem se dar conta da necessidade de se orientar e acompanhar os alunos no decorrer da atividade, como destaca L8.6 (categoria II) quando sugere

deixar os alunos sob orientações de monitores que trabalhem na área da entomologia, pois estes explicariam passo a passo todo o procedimento de coleta entomológica, e do manuseio correto dos insetos a fim de evitar desperdícios e, consequentemente, equilibrar a morte de tantos insetos.

Nestas atividades práticas de ensino, a prioridade dos responsáveis e colaboradores é discutir se as coletas são necessárias e quais as possibilidades alternativas / substitutivas para tais práticas. Caso estas sejam indispensáveis para atingir objetivos do educador e dos alunos, as orientações devem se voltar para o uso adequado dos equipamentos de segurança e a identificação dos animais que podem ser coletados, dispensando animais peçonhentos para não aumentar os riscos de acidentes e os animais com risco de extinção. Para isso, os colaboradores e professores precisam agregar regras e limites às coletas, manipulação e dissecação do material biológico animal, tornando-a compatível "a faixa etária, nível de desenvolvimento e conscientização dos alunos” L10.6 (Categoria II). O mesmo licenciando ainda afirma

concordo que a caixa entomológica e a coleção de material biológico sejam feitas apenas se esse tipo de material não estiver disponível para as aulas práticas e se, também, ele for indispensável à obtenção dos objetivos de aprendizagem pretendidos quando o assunto for abordado (L10.6).

Com os comentários de L10.6, perceberemos que a idéia é de que as coletas não devem ser realizadas se não existirem objetivos específicos e se não forem feitas com responsabilidade. Em uma proposta viável sugerida por L6.6 (Categoria III), teríamos a "construção de um único exemplar de caixa, para que não se faça uma coleta abusiva e indiscriminada dos animais”. Para os adeptos às coleções zoológicas, é uma proposta que não compreenderemos como recurso alternativo, mas como atitude Bioética e de Biossegurança, por reduzir o número de animais coletados e os riscos para os coletores. Em outra possibilidade, confeccionariam coleções temáticas, constituídas por animais "pragas" e vetores que comumente seriam mortos por ocasionarem prejuízos econômicos ou serem associados a risco de doenças, por exemplo: gafanhotos, baratas, formigas, moscas e outros. De acordo com Lima et al. (2008), ainda que não seja uma proposta compartilhada por muitos docentes formadores e em formação, as coleções temáticas se tornam uma opção para a confecção das coleções zoológicas, apresentando temáticas como: animais de importância à saúde; comestíveis; econômicos; pragas agrícolas; invasores de residência, seguidas de orientações quanto às instruções de captura e de sacrifício dos animais, embasadas em orientações da Bioética e da Biossegurança pertinentes à legislação vigente. 
Quadro 1 - Considerações dos licenciandos à proposta de construção de coleções didáticas com animais para aplicação no Ensino Básico (N=34).

\begin{tabular}{|c|c|c|c|c|c|}
\hline \multirow{2}{*}{\multicolumn{2}{|c|}{ CARACTERÍSTICAS }} & \multicolumn{4}{|c|}{ LICENCIANDOS DE 2006.1 / 2008.2} \\
\hline & & \multicolumn{2}{|c|}{$\begin{array}{l}\text { FAVORÁVEIS À COLECCÃO } \\
\qquad(35,3 \% \quad N=12 / 34)\end{array}$} & \multicolumn{2}{|c|}{$\begin{array}{l}\text { NÃO FAVORÁVEIS À COLEC̣̃̃ } \\
(64,7 \% \quad N=22 / 34)\end{array}$} \\
\hline $\mathbf{N}^{0}$ & CATEGORIAS & LICENCIANDO & $\% / \mathbf{N}^{0}$ & LICENCIANDO & $\% / \mathbf{N}^{0}$ \\
\hline I & $\begin{array}{c}\text { Coletar e colecionar } \\
\text { animais para ampliar a } \\
\text { curiosidade e aprendizagem } \\
\text { dos alunos }\end{array}$ & $\begin{array}{l}\text { L3.6 // L8.8, } \\
\text { L10.8, L18.8 }\end{array}$ & $\begin{array}{c}11,8 \% \\
1 \\
4 / 34\end{array}$ & $\cdots$ & $\ldots$ \\
\hline II & $\begin{array}{l}\text { Usar colaboradores } \\
\text { nas atividades práticas } \\
\text { com alunos. }\end{array}$ & $\begin{array}{l}\text { L10.6 // L19.8, } \\
\text { L20.8 }\end{array}$ & $\begin{array}{c}8,8 \% \\
1 \\
3 / 34\end{array}$ & L4.6, L8.6 & $\begin{array}{c}5,9 \% \\
\quad \\
2 / 34\end{array}$ \\
\hline III & $\begin{array}{l}\text { Coletar poucos } \\
\text { exemplares das espécies; }\end{array}$ & $\begin{array}{l}\text { L5.6, L6.6 // L10.8, } \\
\text { L11.8, L13.8, L18.8, } \\
\text { L19.8, L20.8 }\end{array}$ & $\begin{array}{c}23,5 \% \\
1 \\
8 / 34\end{array}$ & $\begin{array}{l}\text { L7.6, L8.6 // L5.8, } \\
\text { L6.8, L12.8 }\end{array}$ & $\begin{array}{c}14,7 \% \\
1 \\
5 / 34\end{array}$ \\
\hline IV & $\begin{array}{l}\text { Conscientizar sobre os } \\
\text { riscos de acidentes com } \\
\text { animais peçonhentos; }\end{array}$ & $\begin{array}{l}\text { L3.6, L5.6, L6.6, } \\
\text { L10.6 // L8.8, L18.8, } \\
\text { L19.8, L20.8 }\end{array}$ & $\begin{array}{c}23,5 \% \\
1 \\
8 / 34\end{array}$ & $\begin{array}{l}\text { L1.6, L4.6, L9.6 / } \\
\text { L17.8 }\end{array}$ & $\begin{array}{l}11,8 \% \\
1 \\
4 / 34\end{array}$ \\
\hline V & $\begin{array}{l}\text { Instigar o uso de } \\
\text { proteccãa / equipamentos } \\
\text { de segurança; }\end{array}$ & $\begin{array}{l}\text { L3.6, L5.6, } \\
\text { L10.6 // L19.8 }\end{array}$ & $\begin{array}{c}11,8 \% \\
/ \\
4 / 34\end{array}$ & L9.6, L11.6 & $\begin{array}{c}5,9 \% \\
1 \\
2 / 34\end{array}$ \\
\hline $\mathrm{VI}$ & $\begin{array}{l}\text { Coletar animais já } \\
\text { encontrados mortos para } \\
\text { montar a coleção }\end{array}$ & $\cdots$ & $\cdots$ & L13.6 || L3.8, L15.8 & $\begin{array}{l}8,8 \% \\
3 / 34\end{array}$ \\
\hline VII & $\begin{array}{l}\text { Solicitar doaç̃ões / } \\
\text { empréstimos de animais a } \\
\text { instituiçõos autorizadas }\end{array}$ & $\cdots$ & $\cdots$ & $\begin{array}{l}\text { L9.6, L13.6 / } \\
\text { L2.8, L6.8 }\end{array}$ & $\begin{array}{l}11,8 \% \\
1 \\
4 / 34\end{array}$ \\
\hline VIII & $\begin{array}{c}\text { Ensinar que matar } \\
\text { animais gera problemas } \\
\text { ao ambiente. }\end{array}$ & $\begin{array}{l}\text { L6.6 // L1.8, L8.8, } \\
\text { L11.8, L18.8, L20.8 }\end{array}$ & $\begin{array}{c}17,6 \% \\
\mid \\
6 / 34\end{array}$ & $\begin{array}{l}\text { L4.6, L9.6, L11.6, L13.6 } \\
\text { |/ L7.8, L9.8, L12.8 } \\
\text { L14.8, L17.8, L21.8 }\end{array}$ & $\begin{array}{c}29,4 \% \\
1 \\
10 / 34\end{array}$ \\
\hline IX & $\begin{array}{c}\text { Perceber o comportamento } \\
\text { dos animais observando-os } \\
\text { no ambiente }\end{array}$ & L6.6 & $\begin{array}{c}3,0 \% \\
1 \\
1 / 34\end{array}$ & $\begin{array}{c}\text { L1.6, L7.6, L9.6, } \\
\text { L12.6 // L5.8, } \\
\text { L9.8, L21.8 }\end{array}$ & $\begin{array}{c}20,6 \% \\
1 \\
7 / 34\end{array}$ \\
\hline$x$ & $\begin{array}{l}\text { Usar recursos alternativos } \\
\text { (tecnológicos ou não tecno- } \\
\text { lógicos) em substituição ao } \\
\text { uso de animais }\end{array}$ & L10.6 // L1.8, L13.8 & $\begin{array}{c}8,8 \% \\
1 \\
3 / 34\end{array}$ & $\begin{array}{c}\text { L2.6, L4.6 // L2.8, L3.8, } \\
\text { L4.8, L6.8, L7.8, L9.8, } \\
\text { L12.8, L14.8, L15.8, } \\
\text { L16.8, L17.8, L21.8 }\end{array}$ & $\begin{array}{l}41,2 \% \\
14 / 24\end{array}$ \\
\hline
\end{tabular}

Ressaltamos os pressupostos da Biossegurança à formação docente dos licenciandos por constatarmos que apenas $35,3 \%$ dos pesquisados esboçam preocupação com acidentes em manuseio de animais, e menos de 20,0\% da amostragem considerariam isso como justificativa para não se fazer coleta e uso de animais em atividades práticas de ensino (categoria IV). São valores muito baixos que afirmam existir desconhecimento e/ou desprezo dos licenciandos que podem 
ser consequência da pouca exploração de seus professores sobre os reais perigos que a manipulação de animais ocasiona, a exemplo do que descrevem Cupo et al. (1991) ao relatar o agravamento dos acidentes se o acidentado for sensível à toxina.

É uma responsabilidade que o educador deve assumir ao estimular e coordenar atividades com manuseio de animais, concepção também destacada por L8.8 ao considerar que "o professor [responsável pela atividade prática] tem por obrigação orientar seus alunos para o risco de acidentes caso certas precauções não sejam tomadas". São atitudes que dizem respeito à reflexão sobre os perigos existentes e à consciência de se usarem periodicamente os equipamentos de segurança como "o uso de luvas, óculos, o uso de tênis, calças compridas e blusas compridas para evitar também picadas de insetos" L5.6 (Categoria V) sempre que participar destas atividades práticas.

Em continuidade, L5.6 ainda destaca a necessidade de se "levar com eles [os coletores] produtos de primeiros socorros para o caso de algum acidente". Identificaremos que se trata de uma observação importante; porém, apenas este licenciando citou essa orientação, tendo em vista que algumas coletas são realizadas em locais distantes dos de atendimento emergencial, o que amplia a necessidade de se dispor desses recursos para os primeiros procedimentos em caso de acidentes. São pressupostos que os manuais de Biossegurança comumente destacam para atividades de pesquisa (BAHIA, 2001), mas não para as atividades práticas de ensino, o que evidencia a importância dessas orientações também para o ensino, aplicadas para a sala de aula, para a formação de novos professores das Ciências Naturais.

$\mathrm{Na}$ (Categoria VI), licenciandos sugerem a utilização de material biológico animal já morto comercializável, a exemplo de aves e partes de mamíferos, ou de animais mortos encontrados em ambientes diversos (estradas, matas, propriedades particulares, ...), a exemplo do que comenta L3.8 quando escreve que os professores e alunos "poderiam fazer as coleções com os animais, desde que fossem encontrados mortos".. Sugestão defendida por pesquisadores como Moraes (2005), pois, de acordo com Brasil (2008) e CFBio (2002), não caracterizaria desrespeito e nem infração. Torna-se mais um recurso metodológico que respeita os procedimentos da Bioética animal, a exemplo de outros procedimentos metodológicos feitos e descritos por autores e pesquisadores como Diniz et al. (2006); Fagundes e Taha (2004); Moraes (2005); Tudury e Potier (2008) que propõem estudos e recursos didático-metodológicos diversificados, voltados para o ensino-aprendizagem, em lugar do uso de animais, o que não faz decair a qualidade da formação profissional dos graduandos.

Para a categoria VII, destaca-se a sugestão de se solicitarem empréstimos e/ou doação do material biológico a instituições autorizadas como as IES formadoras dos professores de Ciências / Biologia. Com isso, evitaríamos os riscos de acidentes ou que estão expostos os alunos do ensino básico em eventuais coletas e montagens dos animais, pois "coleções existem em universidades onde se pode ter um controle maior em relação à segurança e também para não 
retirar animais de seus habitats e dizimá-los sem necessidade" (L13.6). De forma semelhante, L6.8 compreende que seria viável o uso de "coleções já existentes encontradas em museus e parques como o zoológico”, isto é, ambientes que disponibilizam visitas programadas para instituições de Ensino Básico, a exemplo do Espaço Ciências e do Zoológico do Horto de Dois Irmãos, localizados na Região Metropolitana do Recife - PE. Segundo essas propostas, o professor terá a possibilidade de materializar o objeto de estudo, seja por doação ou por visita a ambientes apropriados, o que dispensa a aquisição de material biológico próprio.

São ações possíveis, tendo em vista que a UFPE, UFRPE (Universidade Federal Rural de Pernambuco) e a UPE (Universidade de Pernambuco), importantes instituições públicas de formação de professores no Estado, disponibilizam materiais didáticos e espaço em atividades de extensão para alunos de outras instituições de ensino superior e básico. Estes podem visitar as coleções didático-biológicas dos Departamentos de Zoologia, Botânica, Micologia, Anatomia, Citologia dentre outros durante as programações de eventos como "Conhecendo o Campus" e em visitas agendadas à UFPE (SILVA e VASCONCELOS, 2006). Ainda que sejam atividades de extensão restritas ou pouco divulgadas, são importantes para integrar a sociedade ao conhecimento e aos recursos que IES como a UFPE e outras locais produzem, afim de ampliar os conhecimentos e a interação dos licenciandos. Assim, oportunizam o envolvimento desses graduandos em atividades de monitoria e estágio para a aquisição de recursos didático-metodológicos coerentes ao seu ofício docente, atividades acadêmicas dificilmente assimiladas em situações restritas às disciplinas específicas e pedagógicas do curso.

$\mathrm{Na}$ análise da Categoria VIII, encontraremos comentários de L8.8, considerando que "a coleção de material biológico é uma forma de fixar e aprender na prática as definições e conceitos...[contudo] deve fazer esse tipo de trabalho com responsabilidade, respeitando também o meio ambiente", pois não desprezaríamos a importância da "conscientização ecológica da turma, de como eles estarão interferindo nas relações ecológicas quando extraem o individuo do local” (L6.6). Em outro comentário pertinente dos licenciandos da Categoria VIII, destaca-se o de L7.8 que afirma: "vivemos no mundo onde há espécies em extinção... para que capturar se há outros recursos em mãos?”. Evidencia-se uma preocupação necessária a ser trabalhada ainda na formação do professor, reavaliando danos causados ao ambiente quando se executam coletas desordenadas e sem objetivos pré-definidos e orientados.

Compreenderemos que um docente formador que não apresenta consistência Bioética e de Biossegurança em suas atitudes, dificilmente conseguirá formar discentes com atitudes consistentes e de respeito à vida e aos limites no uso e no convívio do ser humano com outros seres vivos. Se a prática do docente estimular o estudo dos outros seres vivos, observando-os no ambiente natural ou nos locais em que são inseridos, a aprendizagem não se fará distante do que realmente é coerente aprender sobre o ser vivo estudado. É o que dá consistência à 
categoria IX, a exemplo do que sugere L1.6: “eles [os alunos] irão observar não só o animal em si como o local em que é encontrado, seus hábitos alimentares, se é um animal diurno ou noturno, de espreita ou de forrageio, e porque ele tem esses hábitos". Constatarão comportamentos ecológicos característicos de cada espécie, o que não seria possível observar se o animal objeto de estudo estivesse morto.

Para uma maior eficácia, o professor planejará excursões para locais especializados como Parques, Zoológicos ou ambientes mais simples, como os jardins, praças próximas ou espaços internos da escola, de modo que os alunos percebam o comportamento animal, instigando a aprendizagem da forma mais realista possível. Outra possibilidade está no desenvolvimento de espaços ecológicos na própria área da escola, caracterizando-os como um "terrário natural". Tal ambiente será atrativo aos animais que habitam outros ambientes próximos, o que não ocasionará barreiras e nem a necessidade de capturas para estudá-los. Constataremos um compromisso do professor e dos alunos de cuidar do ambiente de forma consciente, condizente à Bioética e à Biossegurança, pois não haverá manuseios, apenas observações do comportamento dos animais no ambiente projetado. Assim, instigaremos o desenvolvimento do saber dos conceitos biológicos de modo mais consistente do que com outras estratégias, como a exposição de animais já mortos, por não propiciar situações provocadoras e nem retratar ambientes naturais dos seres vivos, necessários para um estudo contextualizado das aulas de ciências e biologia.

$\mathrm{Na}$ última categoria $(\mathrm{X})$, a mais significativa dentre os licenciandos, encontra-se a proposta da aplicação de recursos alternativos / substitutivos ao manuseio de animais nas atividades práticas de ensino. Torna-se uma categoria relevante por ser pertinente à Bioética e à Biossegurança, tendo em vista que defende o ensino das ciências e biologia com o uso de recursos tecnológicos como vídeos, data show, software, ou não tecnológicos, como maquetes, modelos confeccionados ou comprados, e/ou de enfoque lúdico, a exemplo da resposta de L10.6

\footnotetext{
existem muitos materiais disponíveis na forma de Atlas, vídeos, jogos, o que não necessitaria a confecção de tais coleções [com animais]; até porque, na maioria das vezes, o material [os animais] é muito pouco diverso e a qualidade não é a desejada para sua reutilização para turmas posteriores.
}

São recursos didático-metodológicos coerentes e pertinentes para o ensino das Ciências / Biologia, a exemplo da afirmação de L7.8: "nós, como biólogos, podemos utilizar recursos didáticos (vídeos, maquetes, caixas já produzidas, etc)" e de L15.8: "a construção de um catálogo virtual de insetos, com fotos ilustrativas" amplia as possibilidades e os recursos do professor, além de serem ações que não agridem e nem ferem parâmetros legais que caminham para a proteção e o bem-estar animal. Com esses recursos, além do estudo morfofisiológico e da classificação dos seres vivos, seriam projetadas situações do comportamento de animais pelo uso dos vídeos e software educativos que, bem 
aplicados, provocam os conflitos necessários à aprendizagem do aluno (AUSUBEL et al., 1980; KRASILCHIK, 2004). Ampliam-se as possibilidades de o professor discutir e simular conceitos da zoologia, da ecologia e da fisiologia humana e comparada, dentre outros conceitos, de forma econômica e concreta à formação conceitual dos alunos.

Com a disponibilidade de recursos e procedimentos diversos, apresentados e discutidos nas categorias e considerações dos licenciandos, teríamos o desencadear de ensino-aprendizagem não dependente do manuseio e do sofrimento de animais. Diminuiríamos os riscos de acidentes entre os alunos que desconhecem os procedimentos de segurança ao manusear animais peçonhentos e produtos químicos nas aulas práticas de laboratório. Contudo, enfatizamos que a eficácia do uso desses recursos pressupõe uma formação diferenciada dos licenciandos das Ciências Biológicas, constituída de novos paradigmas didático-metodológicos que os habilitem a entender os limites e as possibilidades para a relação ensino-aprendizagem dos conceitos científicos. Como diferencial, atuarão com procedimentos e atitudes distintas de concepções que não seguem os princípios da Bioética e da Biossegurança e que negam um ensino das ciências contextualizado à integração da teoria e da prática necessária ao fortalecimento e diversificação no exercício do futuro docente.

Contudo, este estudo não deseja negar a importância do uso de animais para a formação profissional dos licenciandos em relação aos conceitos zoológicos. Aqui se questionam as atitudes que usufruem dos animais como objetos de fácil uso e descarte, e as que insistem em reproduzir, no ensino básico, modelos de aulas práticas só coerentes para a formação superior dos biólogos, sem discutir e apresentar propostas substitutivas e eficazes ao uso de animais na relação ensino-aprendizagem das ciências e biologia na educação básica. Defende-se que uma atividade prática com animais no ensino superior ou básico só teria plena justificativa se, e somente se, desta dependesse todo um processo de ensino-aprendizagem, impossível de ser substituído por outros recursos que também desencadeassem os conflitos necessários à reestruturação mental do aluno.

Tomaremos como coerente defender que "o uso de coleções científicas em escolas de ensino fundamental e médio não se faz necessário” (L15.8), o que estimularia docentes e pesquisadores no Ensino das Ciências a discutirem propostas alternativas ou relevantes visando à aprendizagem dos conceitos zoológicos no ensino básico e na formação dos licenciandos em Ciências Biológicas.

\section{CONSIDERACְ̃̃ES FINAIS}

A ausência de discussões sobre normas e legislação do oficio docente do biólogo compromete as orientações didáticas necessárias à prática dos licenciandos, mediadores de concepções sobre meio ambiente e uso moderado dos animais pela sociedade. Associada a isso, temos a lentidão ou a despreocupação dos 
poderes legais e das IES em se criarem parâmetros Bioéticos e de Biossegurança que orientem as pesquisas e o ensino com animais, a exemplo dos invertebrados sencientes. Existe uma carência de disciplinas específicas voltadas para a formação dos conceitos zoológicos com perspectiva de uso de recursos diversos, prevalecendo saberes disciplinares para um perfil profissional ainda impregnado de concepções e aplicações típicas de um pesquisador, mas não da atuação prática pedagógica de licenciandos das Ciências Biológicas. Em atitudes diversas, as mudanças e conquistas se dão aos poucos, a exemplo do que já preveem as orientações da Lei n. 11.794 (BRASIL, 2008), e do que vêm destacando Marques et al. (2005).

Ainda que muitos dos licenciandos desconsiderem a possibilidade dos riscos de acidentes com os alunos no manuseio de animais em atividades práticas no ensino básico, existem aqueles que conscientemente explorariam tais preocupações nas mais diversas situações de ensino. Para complementar tais iniciativas diagnosticadas, é indispensável responsabilizar as IES e seus professores quanto à criação de condições de ensino que conduzam a uma concepção dominante dos preceitos da Bioética e da Biossegurança com o manuseio de animais nas atitudes dos licenciandos.

Como mecanismo para viabilizar e integrar práticas diversas destinadas ao ensino básico e à formação dos professores de Ciências / Biologia, defende-se a instituição de estudos futuros e da formação de grupos de pesquisa que promovam discussões pertinentes sobre o bem estar animal e os riscos de acidentes no manuseio desses no ensino. Com a viabilização dessa linha de atuação, pode-se imaginar a produção de novos recursos e metodologias compatíveis com a Bioética e a Biossegurança, o que amplia a disponibilidade dos recursos elaborados e testados para o estudo dos conceitos na zoologia e na ecologia, eficazes a tais procedimentos na educação básica e superior. Nisso, teremos que as IES formadoras e seus docentes não podem mais se eximir de suas responsabilidades (GIOVANI, 1998) de viabilizar as condições e estimular seus licenciandos a participar das diversas modalidades extracurriculares de ensino (eventos científicos, grupos de estudos, extensão, ...) que divulguem e conheçam trabalhos e propostas de projetos de ensino-aprendizagem diferenciados para o ensino dos conceitos zoológicos / biológicos.

Consideramos isso como atitude coerente por perceber que existe entre os licenciandos a compreensão da eficácia dos recursos alternativos / substitutivos, procedimento que minimizaria o uso de animais em atividades de ensino, por dar respaldo para o envolvimento destes licenciandos nas mais diversas propostas de ensino diversificado.

É ter confiança nos docentes formadores e nos licenciandos das Ciências Biológicas quanto aos procedimentos didático-metodológicos que respeitem a eficácia dos recursos alternativos / substitutivos, acreditando que estes não desqualificam os percursos necessários para a aprendizagem dos conceitos científicos, a exemplo do que defendem Diniz et al. (2006), Moraes (2005) e Tudury \& Potier (2008).

Como resultado mais prático para o ensino das ciências, entendemos que a formação de docentes das ciências / biologia com a preocupação do bem estar dos seres manipulados, como também dos sujeitos que manipulam estes animais, 
tratamos não apenas os princípios da Bioética (Bem-Estar Animal) e da Biossegurança (Redução dos Riscos de Acidentes), mas, muito mais, da ampliação das possibilidades de um bom uso dos recursos na relação ensino aprendizagem dos saberes científicos. Acreditamos que com a mudança de atitudes ampliaremos também a confiança de que as atividades práticas, com segurança, não dependem de espaços determinados - a exemplo dos laboratórios - mas de espaços construídos e pensados para um momento pedagógico de aprendizagem em que os sujeitos se socializam e discutem suas percepções e suas experiências a respeito dos fenômenos observados. Teremos maior suporte para repensarmos estratégias de aprendizagem em espaços não formais, como também, nas atividades expostas e vivenciadas nas Feiras de Ciências. Em ambos os espaços, a preocupação com os cuidados não inviabiliza a dinâmica necessária para um bom resultado; mas permite-nos compreender que esses momentos pedagógicos ampliam sua significância em determinadas atividades práticas mais interativas, diferentemente daquelas em que o aluno apenas observa o professor executar as etapas da atividade.

\section{REFERÊNCIAS}

ANVISA - Agência Nacional de Vigilância Sanitária. Biossegurança. Revista Saúde Pública, v.39, n.6. 2005. AUSUBEL, D. P.; NOVAK, J. D.; HANESIAN, H. Psicologia Educacional, 2 ed. Rio de Janeiro: Interamericana, 1980. BAHIA, Secretaria da Saúde - Diretoria de Vigilância e Controle Sanitário, UFBA, Instituto de Ciências da Saúde. Manual de Biossegurança. Salvador, 2001.

BARDIN, L. Análise de Conteúdo, 3 ed. Lisboa: Edições 70, 2004.

BASTOS, J. C. F.; RANGEL, A. M. PAIXÃO, R. L.; REGO, S. Implicações Éticas do Uso de Animais no Processo de Ensino-Aprendizagem nas Faculdades de Medicina do Rio de Janeiro e Niterói. Revista Brasileira de Educação Médica, v26, n3, p.162-170, 2002.

BRASIL, Constituição da República Federativa do Brasil, Brasília, 1988.

, Decreto n. ${ }^{\circ} 3.179$, Brasília, 1999a. Disponível em www.planalto.gov.br/ccivil/leis. Último acesso em 10 fev. 2010.

, LDB (Lei n. 9.394 - Diretrizes e Bases), Brasilia: MEC, 1996. Disponível em www.mec.gov. br/Sesu/diretriz. Último acesso em 20 nov. 2009.

Lei n. 9.605, Brasília, 1998. Disponível em www.planalto.gov.br/ccivil/leis/L9605. Último acesso em 02 de fevereiro de 2007.

LEI $n^{0}$ 11.794, Brasília, 2008. Disponível em www.planalto.gov.br/Ccivil_03/_Ato20072010/2008/Lei/L11794.htm. Último acesso em 10 jan. 2010.

Parâmetros Curriculares Nacionais PCN: Ensino Médio. Brasília: MEC, 1999b. Disponível em www.mec.gov.br/Sesu/diretriz. Último acesso em 11 out. 2009.

- Orientacões Curriculares para o Ensino Médio (OCEM): Ciências Naturais, Matemática e suas Tecnologias. Brasillia: MEC, 2006. Disponível em www.mec.gov.br/seb/arquivos. Último acesso em 10 de fevereiro de 2010. , PCN+ Ensino Médio: Orientações educacionais complementares aos Parâmetros Curriculares Nacionais, Brasilia: MEC, 2002. Disponível em www.mec.gov.br/Sesu/diretriz. Último acesso em 12 jan. 2010. CFBio (Conselho Federal de Biologia) - Resolução $N^{\circ}$ 2, 2002. Disponível em www.cfbio.gov.br. Último acesso em 16 jan. 2010.

COBEA (Colégio Brasileiro de Experimentação Animal) / CARDOSO, C. V. P. Leis Referentes à Experimentação Animal no Brasil - Situação Atual. Disponível em www.cobea.org.br/etica. Último acesso em 01 fev. 2009. CUPO, P.; AZEVEDO-MARQUES, M. M.; MENEZES, J. B.; HERING, S. E. Reações de hipersensibilidade imediatas após uso intravenoso de soros antivenenos: valor prognóstico dos testes de sensibilidade 
intradérmicos. Revista do Instituto de Medicina Tropical de São Paulo, São Paulo, v. 33, n. 2, p. 115-122, 1991. DIAS-DA-SILVA, M. H. G. F. - O professor e seu desenvolvimento profissional: Superando a concepção do algoz incompetente. Caderno CEDES, v.19, n. 44, p.33-45, 1998.

DINIZ, R.; DUARTE, A. L. A.; OLIVEIRA, C. A. S; ROMITI, M. Animais em aulas práticas: podemos substituí-los com a mesma qualidade de ensino ? Revista Brasileira de Educasaão Médica, v. 2, n.30, p. 31-41, 2006. FAGUNDES, D. J.; TAHA, M. O. Modelo animal de doença: critérios de escolha e espécies de animais de uso corrente. Acta Cirúrgica Brasileira, v.19, n.1, p.59-65, 2004.

FEIJÓ, A. G. S.; SANDERS, A.; CENTURIÃO, A. D.; RODRIGUES, G. S.; SCHWANKE, C. H. A. Análise de indicadores éticos do uso de animais na investigação científica e no ensino em uma amostra universitária da Área da Saúde e das Ciências Biológicas. Scientia Medica, v.18, n.1, p.10-19, 2008.

GALLIAN, D. M. C. Por detrás do último ato da ciência-espetáculo: as células-tronco embrionárias. Revista de Estudos Avançados, v. 19, n. 55, p.251-260, 2005.

GARRAFA, V. Os Limites da Ética e da Moral na Pesquisa Cientifica. Humanidade - Biologia, Ed. UnB, n.48, p. 209-213, 2001.

GIOVANI, L. M. - Do professor informante ao professor parceiro: Reflexões sobre o papel da universidade para o desenvolvimento profissionais de professores e as mudanças nas escolas - Caderno CEDES, v.19, n.44, p.46-58, 1998 .

HOUGHTON, P. J.; HYLANDS, P.J.; MENSAH, A. Y.; DETERS, A. M. In vitro tests and ethnopharmacological investigations: Wound healing as an example. Journal of Ethnopharmacology, v.100, Issues 1-2, 22, p.100-107, 2005.

IBAMA, Lista da Fauna Brasileira Ameaçada de Extinção. Disponível em www.ibama.gov.br/fauna/ cetas. Último acesso em 01 nov. 2009.

KRASILCHIK, M. Prática de Ensino de Biologia, 4 ed. São Paulo: USP, 2004.

LABARTHE, N.; ALMEIDA, F. M.; FARIA, M. C. F.; REMY, G. L.; CHAME, M. Uso de animais: os fins justificam os meios? In: SCHRAMM, F. R.; REGO, S.; BRAZ, M. PALÁCIOS, M. Bioética, Riscos e Proteção - Rio de Janeiro: UFRJ/ Fiocruz, 2005.

LIMA, K. E. C.; VASCONCELOS, S. D. Acidentes com animais peçonhentos: um estudo etnozoológico com agricultores de Tacaratu, Sertão Pernambucano. Sitientibus - Série Ciências Biológicas, UEFS - BA, v. 6, n. 2, p.138-143, 2006.

LIMA, K. E. C.; MAYER, M.; CARNEIRO-LEÃO, A. M.; VASCONCELOS, S. D. Conflito ou Convergência? Percepções de professores e licenciandos sobre ética no uso de animais no ensino de zoologia. Revista Investigações em Ensino de Ciências, v. 13, n. 3, p.353-369, 2008.

LUNA, S. P. L. Dor, senciencia e bem-estar em animais. In: Anais do I Congresso Brasileiro de Bioética e Bem-estar Animal \& I Seminário Nacional de Biossegurança e Biotecnologia Animal, Recife - PE, p.27-30, 2008. MACHADO, J. G. S.; PINHEIRO, M. S.; MARÇAL, S. H.; ALCÂNTARA, P. F. P. Análise bioética da legislação brasileira aplicável ao uso de animais não-humanos em experimentos científicos. Revista de Saúde do Distrito Federal, v. 15, nº 3/4, p.09-21, 2004.

MARQUES, R. G.; MIRANDA, M. L.; CAETANO, C. E. R.; BIONDO-SIMÕES, M. de L. P. Rumo à regulamentação da utilização de animais no ensino e na pesquisa científica no Brasil. Acta Cirúrgica do Brasileira., v.20, n.3, p.262-267, 2005.

MORAES, C. G. O Uso didático de animais vivos e os métodos substitutivos em Medicina Veterinária. Monografia de conclusão de curso Veterinária, depositada sobre o n. M36L, Universidade Anhembi Morumbi (UAM) - São Paulo, 2005.

PAIXÃO, R. L. Aspectos éticos nas regulamentações das pesquisas em animais. In. SCHRAMM, F. R.; REGO, S.; BRAZ, M.; PALÁCIOS, M. Bioética, Riscos e Proteção - Rio de Janeiro: UFRJ / Fiocruz, 2005. PAIXÃO, R. L. Experimentação animal: raz̃ões e emoģẽes para uma ética. Fundação Oswaldo Cruz, Escola Nacional de Saúde Pública; 2001. Disponível em www.portalteses.cict.fiocruz.br/transf.php. Último acesso em 01 out. 2009.

PIMENTA, L. G.; SILVA, A. L. Ética e Experimentação animal. Acta Cirrírgica Brasileira, v.16 n.4, p.255-260, 2001. QUADROS, A. L.; CARVALHO, E.; COELHO, F. dos S.; SALVIANO, L. GOMES, M. F. P. A.; MENDONÇA, P. C.; BARBOSA, R. K. Os professores que tivemos e a formação da nossa identidade como docentes. ENSAIO: Pesquisa em Educação em Ciências, v. 7, n. 1, p.01-08, 2005. 
RAYMUNDO, M. M.; GOLDIM, J. R. Ética da pesquisa em modelos animais. Revista de Bioética e Ética Médica, v.10 n.1, p. 31-44, 2002.

RIVERA, E. A. Ética na Experimentação Animal, In: Animais de Laboratório: criação e Experimentação, Rio de Janeiro: Fiocruz, 2002.

SILVA, M. S.; VASCONCELOS, S. D. Extensão Universitária e Formação Profissional em Biologia: Avaliação da Experiência da Universidade Federal de Pernambuco. Estudos em Avaliação Educacional, v. 17, n. 33, p. 119-135, 2006.

SILVA, P. Farmacologia. 6 edição, Rio de Janeiro: Guanabara, 2002.

SINGER, P. Libertacão animal. Tradução Marly Winckler. Edição Revista - Porto Alegre, São Paulo: Lugano, 2004. SOUTO, A. Etologia: princípios e reflexões. Recife: Universitária da UFPE, 2003.

TEIXEIRA, P.; VALLE, S. Riscos Biológicos em Laboratórios, In: VALLE, S.; TELLES, J. L. (Org) Bioética e biorrisco: abordagem transdisciplinar. Rio de Janeiro: Interciência, p. 171-201, 2003.

TELLES, J. L. Bioética, biotecnologias e biossegurança: desafios para o século XXI. In: VALLE, S.; TELLES, J. L. (Org) Bioética e biorrisco: abordagem transdisciplinar. Rio de Janeiro: Interciência, p. 171-201, 2003. TUDURY, E. A.; POTIER, G. M. Métodos substitutivos ao uso de animais vivos no ensino: Métodos alternativos para aprendizado prático da disciplina técnica cirúrgica veterinária. In: Anais do I Congresso Brasileiro de Bioética e Bem-estar Animal \& I Seminário Nacional de Biossegurança e Biotecnologia Animal, Recife - PE, p. 92-95, 2008.

VENTURA, M. U.; PANIZZI, A. R. Megalotomus parvus West. (Hemiptera: Alydidae): inseto adequado para experimentação e didática entomológica. Anais da Sociedade Entomológica do Brasil, v.26 n.3, p.579-581, 1997.

\section{Apêndice 01}

Problematização Identificação do licenciando:

Em um colégio da rede particular, deseja-se estruturar materiais didáticos para o Ensino Fundamental e Médio. Um dos professores de Biologia sugeriu aos seus alunos a confecção de uma caixa entomológica e a organização de uma coleção com outros animais, dentre os quais alguns serão conservados a seco; outros, em solução de formol e álcool. Os alunos terão a responsabilidade de coletar, montar e conservar o material que ficará exposto no colégio.

A direção gostou desta idéia, apoiando a proposta do professor. Você, também como professor de Biologia deste colégio, que recomendações e sugestões apresentaria a seus alunos? Concorda que a caixa entomológica e a coleção com demais animais sejam feitas? Caso sim, que recomendações daria? Caso não, o que sugeriria como alternativa para a não realização desta atividade?

Utilize-se de aspectos da Bioética e Biossegurança para a orientação aos seus alunos na obtenção dos recursos didáticos solicitados ou dos recursos alternativos.

Data de Recebimento: 21/05/2010

Data de Aprovação: 12/10/2011

Data da Versão Final: 21/10/2011 
